\title{
Molecular-based cross-species evaluation of bovine coronavirus infection in cattle, sheep and goats in Ghana
}

Vitus Burimuah ${ }^{1,2,3^{*}}$, Augustina Sylverken ${ }^{3,4}$, Michael Owusu ${ }^{3,5}$, Philip El-Duah ${ }^{1,3,6}$, Richmond Yeboah ${ }^{1,3}$, Jones Lamptey ${ }^{1,3}$, Yaw Oppong Frimpong ${ }^{3,7}$, Olivia Agbenyega ${ }^{8}$, Raphael Folitse ${ }^{2}$, Ben Emikpe ${ }^{2}$, William Tasiame ${ }^{2,6}$, Eddie-Williams Owiredu ${ }^{9}$, Samuel Oppong ${ }^{10}$, Christopher Antwi ${ }^{7}$, Yaw Adu-Sarkodie ${ }^{1}$ and Christian Drosten ${ }^{6}$

\begin{abstract}
Background: Apart from the huge worldwide economic losses often occasioned by bovine coronavirus (BCoV) to the livestock industry, particularly with respect to cattle rearing, continuous surveillance of the virus in cattle and small ruminants is essential in monitoring variations in the virus that could enhance host switching. In this study, we collected rectal swabs from a total of 1,498 cattle, sheep and goats. BCoV detection was based on reverse transcriptase polymerase chain reaction. Sanger sequencing of the partial RNA-dependent RNA polymerase (RdRp) region for postive samples were done and nucleotide sequences were compared with homologous sequences from the GenBank.

Results: The study reports a BCoV prevalence of $0.3 \%$, consisting of 4 positive cases; 3 goats and 1 cattle. Less than $10 \%$ of all the animals sampled showed clinical signs such as diarrhea and respiratory distress except for high temperature which occurred in > 1000 of the animals. However, none of the 4 BCoV positive animals manifested any clinical signs of the infection at the time of sample collection. Bayesian majority-rule cladogram comparing partial and full length BCoV RdRp genes obtained in the study to data from the GenBank revealed that the sequences obtained from this study formed one large monophyletic group with those from different species and countries. The goat sequences were similar to each other and clustered within the same clade. No major variations were thus observed between our isolates and those from elsewhere.
\end{abstract}

(Continued on next page)

\footnotetext{
* Correspondence: vitus7uk@yahoo.co.uk

'Department of Clinical Microbiology, Kwame Nkrumah University of Science and Technology, Kumasi, Ghana

${ }^{2}$ School of Veterinary Medicine, Kwame Nkrumah University of Science and Technology, Kumasi, Ghana

Full list of author information is available at the end of the article
}

(C) The Author(s). 2020 Open Access This article is licensed under a Creative Commons Attribution 4.0 International License, which permits use, sharing, adaptation, distribution and reproduction in any medium or format, as long as you give appropriate credit to the original author(s) and the source, provide a link to the Creative Commons licence, and indicate if changes were made. The images or other third party material in this article are included in the article's Creative Commons licence, unless indicated otherwise in a credit line to the material. If material is not included in the article's Creative Commons licence and your intended use is not permitted by statutory regulation or exceeds the permitted use, you will need to obtain permission directly from the copyright holder. To view a copy of this licence, visit http://creativecommons.org/licenses/by/4.0/ The Creative Commons Public Domain Dedication waiver (http://creativecommons.org/publicdomain/zero/1.0/) applies to the data made available in this article, unless otherwise stated in a credit line to the data. 
(Continued from previous page)

Conclusions: Given that Ghana predominantly practices the extensive and semi-intensive systems of animal rearing, our study highlights the potential for spillover of BCoV to small ruminants in settings with mixed husbandry and limited separation between species.

Keywords: Bovine coronavirus, Cattle, Sheep, Goat, Cross-species infection

\section{Background}

Bovine Coronavirus (BCoV) belongs to the genus Betacoronavirus within the Coronaviridae family [1-3]. It is an enveloped, single-stranded and positive-sense RNA virus with a genome size of $32 \mathrm{~kb}$, encoding five main structural proteins: the nucleocapsid, the hemagglutinin esterase, the membrane, the spike $(\mathrm{S})$, and the envelope proteins [4].

$\mathrm{BCoV}$ has been implicated in severe diarrhea in neonatal calves, winter dysentery in adult cattle and has been associated with respiratory infections in calves and feedlot cattle $[5,6]$. Transmission is primarily through respiratory or fecal-oral routes [7], infecting the respiratory (nasal, tracheal, and lung) and intestinal (villi and crypts of the ileum and colon) epithelial cells [8]. Although infection with $\mathrm{BCoV}$ has a low mortality, it generally presents with a high morbidity among cattle of all ages [9]. Outbreaks characteristically occur in autumn and winter, when the virus is most active $[10,11]$. Substantial economic toll can be exerted by $\mathrm{BCoV}$ infection when a large herd are infected, resulting in drastic reduction in milk yield $[12,13]$.

In many developing countries where different animals live in close proximity, there is the possibility of interspecies transmission of zoonotic diseases. A few studies have reported the detection of $\mathrm{BCoV}$ in small ruminants [14-18].
Despite the health and economic significance of $\mathrm{BCoV}$ in livestock, only limited studies have been conducted to evaluate $\mathrm{BCoV}$ infection in livestock in Ghana to date. We have recently reported a high seroprevalence, crossspecies infection and serological determinants of $\mathrm{BCoV}$ in cattle, sheep and goats in Ghana [19]. In this study, we employed a molecular-based detection method to investigate the presence of $\mathrm{BCoVs}$ in rectal samples of cattle, sheep and goats from four major regions in Ghana. We also characterized, for the first time, the occurrence and the molecular phylogeny of the BCoVs within the selected regions.

\section{Results}

\section{The prevalence of $\mathrm{BCoV}$}

Molecular detection of $\mathrm{BCoV}$ was based on the use of the RNA-dependent RNA polymerase (RdRp) gene. The prevalence of $\mathrm{BCoV}$ in the entire animal population was $0.3 \%(4 / 1,498)$ (Figs. 1 and $2 \mathrm{a})$. Out of the 4 positive cases, 3 were goats whereas 1 was cattle (Fig. 2b). Based on stratification by the sampling regions, the three $\mathrm{BCoV}$ positive goats were from the Upper East region while the $\mathrm{BCoV}$ positive cattle was from the Volta region (Fig. 2c).

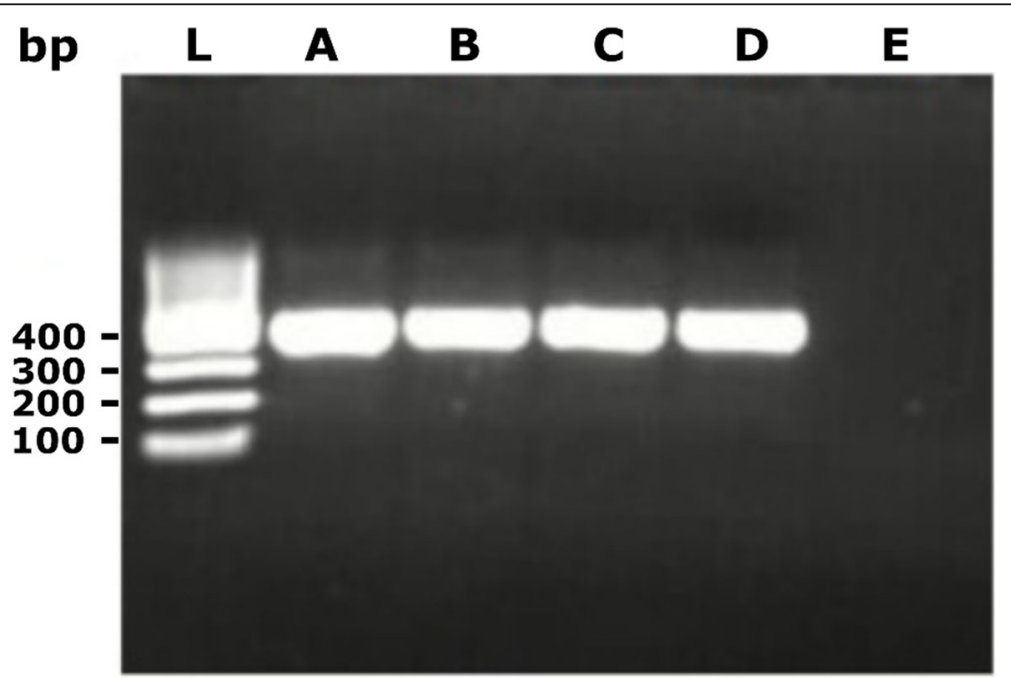

Fig. 1 Gel image of the Hemi-nested PCR products used for sequencing. L: 100 bp ladder; A: goat 1; B: goat 2; C: goat 3; D: cattle 1; E: negative control. All products were at the expected size of $404 \mathrm{bp}$ 


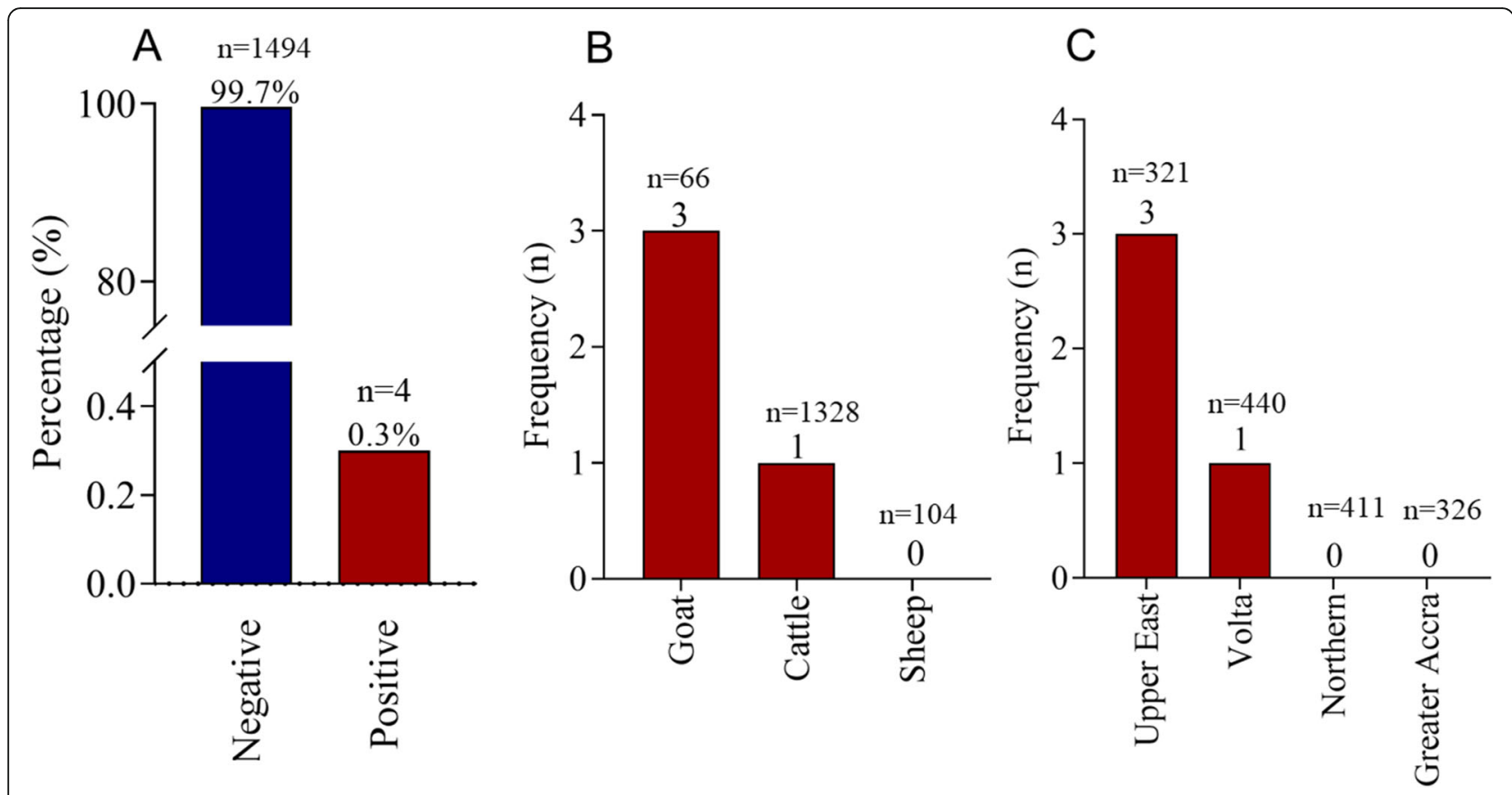

Fig. 2 The prevalence of BCoV. a Overall prevalence of BCoV among the 1498 animals. b Number of BCoV positive cases per type of animal. c Number of BCoV positive cases per region. $\boldsymbol{n}$ represented the total number of animals in each group

\section{Sequencing of the RdRp region}

Sequencing was performed on the partial RdRp region of the four bovine coronavirus isolates. The three goat sequences were identical to each other and were $98.56 \%$ similar to the cattle sequence based on percentage sequence identity. There were three nucleotide substitutions between the goat sequences in comparison to the cattle sequence. Comparing all sequences to a reference bovine coronavirus sequence from GenBank (Accession number: NC_003045) showed nucleotide substitutions at positions $15281 \mathrm{C}>\mathrm{T}$ and $153,511 \mathrm{~T}>\mathrm{A}$ for the goat samples, and at 15,272 G > T, 15,291 C > T, 15,311 T > C and $15,446 \mathrm{G}>\mathrm{A}$ for the cattle sample. Figure 3 shows a cladogram constructed for all four bovine coronaviruses identified in goats and cattle. Sequences obtained from this study formed one large monophyletic group with those from different species and countries. The goat sequences were similar to each other and clustered within the same clade. Hence, no major variations were observed with our isolates and those from elsewhere. All sequences were submitted to NCBI and were assigned accession numbers MT711466 to MT711469.

\section{Discussion}

In a prior study, we reported a high seroprevalence, cross-species infection and serological determinants of $\mathrm{BCoV}$ in cattle, sheep and goats in Ghana [19]. We found the seroprevalence to be higher in cattle, followed by goats and sheep. For cattle, seroprevalence was significantly higher on larger farms and in the northern region of Ghana, where the climate is relatively dry. In this study, we sought to investigate the presence of BCoVs in rectal samples of cattle, sheep and goats from four major regions in Ghana using molecular-based detection method. We also aimed to characterize the molecular phylogeny of the BCoVs within the selected regions.

This is the first report on molecular detection and phylogenetic analysis of $\mathrm{BCoV}$ infection in both cattle and small ruminants in Ghana. The molecular prevalence of $\mathrm{BCoV}$ was $0.3 \%$. Among the positive cases, $0.2 \%$ were samples obtained from the Upper East region whereas $0.1 \%$ was from the Volta region. Greater Accra and Northern regions did not record positive cases. Strikingly, upon stratification by animal type, three out of the four BCoV positive cases were goats whereas one was cattle. No case was recorded in sheep.

The prevalence of $\mathrm{BCoV}$ in this study is lower compared to previous studies. A study by Lojkić et al. in Croatia (2015) found 82 of the 101 analyzed fecal and three nasal samples (81\%) to be positive for $\mathrm{BCoV}$ by RT-PCR [9]. Another study by Kumar et al. in India reported $9.38 \%(15 / 160)$ prevalence of BCoV in cattle [20]. The higher prevalence in these studies could be due to the fact that they considered only cattle that were symptomatic, presenting with diarrhea. This potentiates the likelihood of obtaining samples that are positive for 


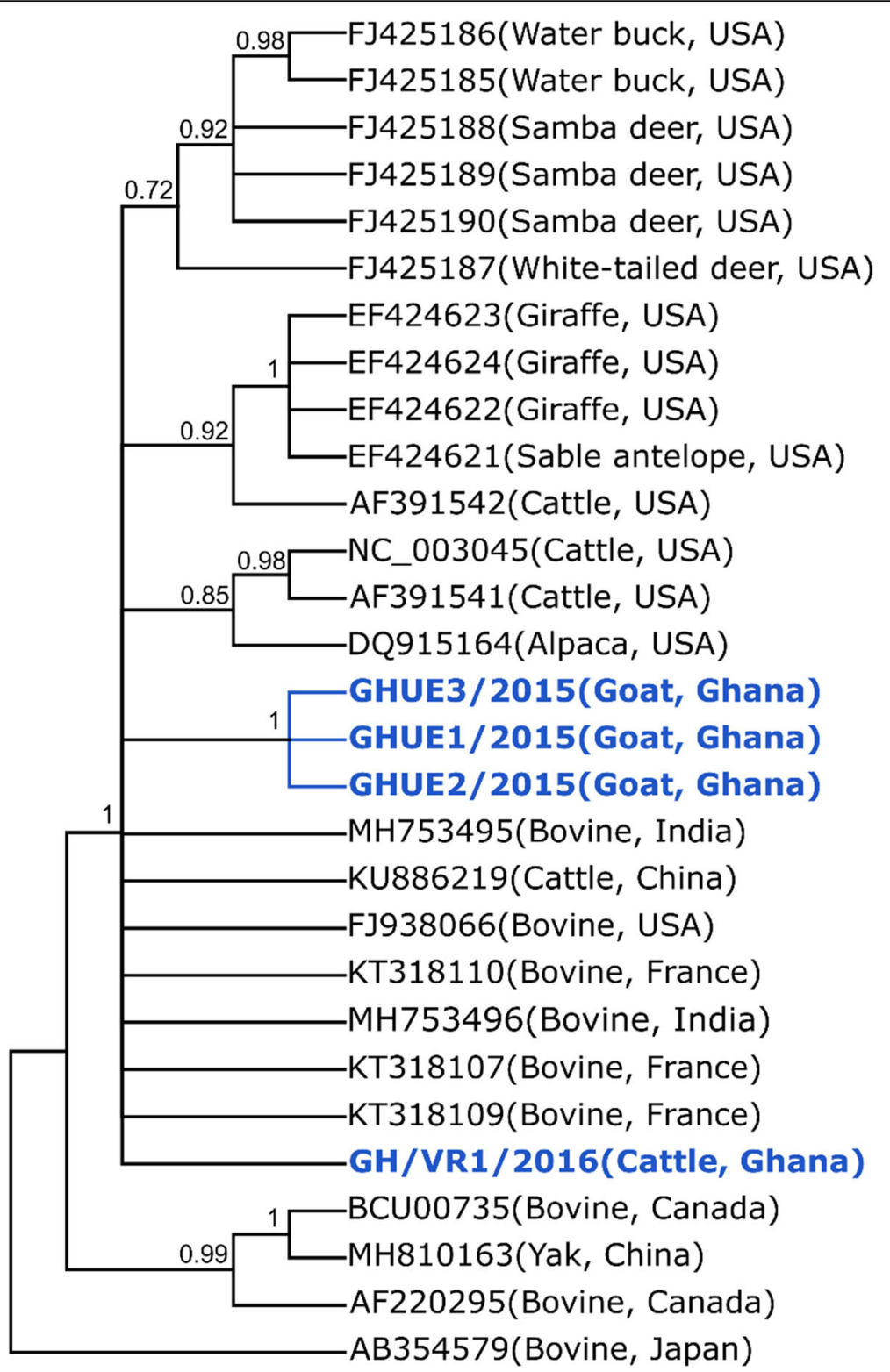

Fig. 3 Bayesian majority-rule cladogram comparing partial and full length BCoV RdRp obtained in the study to those from different species and countries

$\mathrm{BCoV}$ compared to large-scale randomized screening used in this study. Studies by Lathrop et al. [21], Cho et al. [22], and Hasoksuz et al. [23] also reported a similarly high prevalence of $\mathrm{BCoV}$ in the USA. Other factors that could account for the lower prevalence in this study are the disparities in geographical location and timing of sampling relative to viral shedding. Of note, $\mathrm{BCoV}$ persists longer in lower temperatures and therefore is able to remain active in the environment all year round in temperate regions compared to the tropical region. Additionally, differences in animal management systems between developing countries such as Ghana and the developed countries could account for the differences in prevalence rates.

Smith et al. indicated that farm management systems have a significant influence on $\mathrm{BCoV}$ infection rate [24]. In Ghana, the extensive and semi-intensive systems are largely practiced in cattle, sheep, and goats rearing. On the other hand, the feedlot system of management is a commonly practiced system in most developed countries. This system is a variant of intensive farming practice where animals are confined throughout the year. Such relatively close confinement could enhance the transmissibility of BCoV infection within herds or flocks, thus increasing the detection 
rate of the virus. Furthermore, $\mathrm{BCoV}$ infection is generally self-limiting [25]. Viral shedding is transient and is known to last for only about 9 days. Given that sampling of this study was randomized, with almost all the animals included being asymptomatic, it is possible that sampling was done at a time when viral shedding had terminated.

In Ghana and many developing countries, different animals live in proximity to one another. There is thus the need to investigate cross-species infection because the close and sustained interaction between different animals poses an increased risk of spillover of communicable diseases between animals. However, globally, there are only a few studies evaluating the prevalence of $\mathrm{BCoV}$ in non-cattle livestock [14-18]. The presence of $\mathrm{BCoV}$ in three goats out of the four $\mathrm{BCoV}$ positive cases, thus, indicates a possible active infection and provides update information of spillover of $\mathrm{BCoV}$ from cattle to small ruminants in Ghana. It is instructive to state that in Ghana, mixed farming (livestock) is what is largely practiced by farmers and this predispose animals to crossspecies infections. The higher prevalence of $\mathrm{BCoV}$ observed in goats compared to cattle is interesting, especially when the number of cattle samples were higher than goat samples and the fact that $\mathrm{BCoV}$ show tropism for cattle. This can be explained by the role of proximity in the spread of $\mathrm{BCoV}$. All the three $\mathrm{BCoV}$ positive goats were from one farm in the Upper East region (Northern Ghana) while the BCoV positive cattle was from the Volta region (Southern Ghana). Additionally, these farms had mixed species. It is important to note that none of the animals which tested positive for $\mathrm{BCoV}$ showed clinical signs at the time of sample collection.

Comparison of the nucleotide sequences obtained in this study with sequence data contained in the National Center for Biotechnology Information (NCBI) GenBank revealed no major differences. Three of the four bovine coronavirus isolated were found in goats and one from cattle. Sequences obtained from the goats (Ghana Goat 1-3) were similar to each other and clustered within the same clade. Likewise, the sequence obtained from cattle (Ghana cattle) was also similar to those from other countries. Hence, no major variations were observed with our isolates and those from elsewhere. However, this finding corroborates our previous deposition of the possible interspecies transmission of $\mathrm{BCoV}$ from cattle and wildlife to small ruminants [19].

Of note, given the relatively higher prevalence of $\mathrm{BcoV}$ in goats compared to cattle, it will be important for future studies to consider sequence analysis of regions other than the highly conserved RdRp. This would be beneficial for phylogenetic analysis of $\mathrm{BCoV}$ strains found in goats.

\section{Conclusions}

Given that Ghana predominantly practice the extensive and semi-intensive systems of animal rearing, our study highlights the potential for spillover of $\mathrm{BCoV}$ to small ruminants in settings with mixed husbandry and limited separation between species.

\section{Methods \\ Study design/area and data collection}

This was a cross-sectional study conducted from January 2015 to December 2018 in Ghana. Animals included in this study consist of 66 goats, 104 sheep and 1,328 cattle from five different districts in Ghana. A simple twostage cluster sampling technique was used as previously described [19]. The districts included were North Tongu in Volta, Bongo District in the Upper East, Ada West in Greater Accra and Savelugu and Wale wale in Northern region. The number of farms and animal species from the four regions are shown in Table 1.

\section{Sample collection, processing and analysis}

Rectal swabs were collected from each animal using sterile swab sticks. The swabs were placed in pre-labeled cryotubes (SARSTADT, Nümbrecht, Germany) containing a viral RNA stabilization solution, RNAlater (Applied Biosystems, Foster City, CA, USA). Samples were then transported to the Kumasi Centre for Collaborative Research (KCCR) for storage at $-70{ }^{\circ} \mathrm{C}$ prior to laboratory analysis.

Data and sample collection was done on the owners' farms and in their presence, after which animals were released back to the owners. Less than $10 \%$ of all the animals sampled showed clinical signs such as diarrhea and

Table 1 Number of farms and animal species from the four regions

\begin{tabular}{|c|c|c|c|c|c|c|c|c|c|c|c|c|c|}
\hline \multirow{2}{*}{$\frac{\text { Regions }}{\text { Animals }}$} & \multicolumn{3}{|c|}{ Upper East } & \multicolumn{3}{|c|}{ Northern } & \multicolumn{3}{|c|}{ Greater Accra } & \multicolumn{3}{|c|}{ Volta } & \multirow[t]{2}{*}{ Total } \\
\hline & F1 & $\mathrm{F} 2$ & F3 & F1 & F2 & F3 & F1 & F2 & F3 & F1 & $F 2$ & F3 & \\
\hline Cattle & 68 & 100 & 100 & 103 & 131 & 127 & 100 & 100 & 100 & 157 & 139 & 103 & 1328 \\
\hline Sheep & 21 & 0 & 0 & 12 & 13 & 6 & 10 & 3 & 6 & 12 & 14 & 7 & 104 \\
\hline Goat & 11 & 9 & 12 & 8 & 4 & 7 & 2 & 1 & 4 & 0 & 5 & 3 & 66 \\
\hline Grand Total & 100 & 109 & 112 & 123 & 148 & 140 & 112 & 104 & 110 & 169 & 158 & 113 & 1,498 \\
\hline
\end{tabular}

F: farms; The three livestock from various households close to each other were pooled together to form a single farm 
respiratory distress except for high temperature which occurred in $>1000$ of the animals [19].

\section{Processing of rectal swabs for RNA extraction}

Prior to RNA extraction and subsequent laboratory analysis, rectal samples were thawed at room temperature and vortexed. This was followed by centrifugation at $4000 \mathrm{~g}$ for $1-2 \mathrm{~min}$ before aliquoting $140 \mu \mathrm{l}$ into new sterile tubes.

\section{Testing of faecal swabs from cattle, sheep, and goats using RT-PCR \\ Viral RNA extraction}

Viral RNA was extracted from all 1,498 samples using the spin protocol of the QIAamp Viral RNA Mini kit (Qiagen, Hilden, Germany) following the manufacturer's instruction. The RNA was eluted in $100 \mu \mathrm{l}$ of buffer AVE (pre-warmed at $80^{\circ} \mathrm{C}$ ). The eluted RNA was stored at $-20^{\circ} \mathrm{C}$ until they were tested for $\mathrm{BCoV}$ using real-time polymerase chain reaction (RT-PCR).

\section{PCR product generation}

Detection of bovine CoV RNA was carried out using OneStep RT-PCR Kit (Qiagen, Hilden, Germany) and HCoVOC43 primers. The following thermal protocol was used: reverse transcription at $50{ }^{\circ} \mathrm{C}$ for $30 \mathrm{~min}$, Taq polymerase inactivation at $95^{\circ} \mathrm{C}$ for $15 \mathrm{~min}, 45$ cycles of $95^{\circ} \mathrm{C}$ for 15 secs, and $60^{\circ} \mathrm{C}$ for 30 secs. Amplification results were acquired at $60{ }^{\circ} \mathrm{C}$. The total volume of the Qiagen one-step Master Mix was $25 \mu \mathrm{l}$ per sample comprised of RNAsefree water $(10.5 \mu \mathrm{l})$; Onestep $5 \mathrm{x}$ buffer $(5 \mu \mathrm{l})$; dNTP $(1 \mu \mathrm{l})$; Forward primer $(1 \mu \mathrm{l})$; Reverse primer $(1 \mu \mathrm{l})$; OC43 probe $(0.5 \mu \mathrm{l})$; enzyme mix $(1 \mu \mathrm{l})$ and the $5 \mu \mathrm{l}$ of the RNA template. The oligonucleotide sequences of the forward and reverse primers used for the amplification were CGATGA GGCTATTCCGACTAGGT and CCTTCCTGAGCCTT CAATATAGTAACC respectively, and the probe sequence used was TCCGCCTGGCACGGTACTCCCT as previously described [26]. All RNA extracts were tested for host DNA to determine successful nucleic acid purification prior to use in PCR testing.

\section{Purification of DNA products for sequencing}

All bovine coronavirus positive samples were confirmed by means of 1-step reverse transcription-heminested PCR, using primers CoV2A-F (CTTATGGGTTGGGATTATCC) and CoV2A-R (TAATAACAGACAACGCCATCATC) for the first round and the inner primers CoV2A-Rnest a (CCAT CATCACTCAGAATCATCA) and CoV2A-Rnest b (CCAT CATCAGAAAGAATCATCA) as previously described [27]. This generated a 404-base pair amplicon from the RNAdependent RNA polymerase (RdRp) gene (Additional file 1: Original uncroppped gel image). The detection and sequence analysis were based on the $\mathrm{RdRp}$ region because it is a highly conserved region which will facilate broad detection capability across the Betacoronavirus clade $2 \mathrm{a}$.

The PCR products were then prepared for Sanger sequencing by mixing $5 \mu \mathrm{L}$ of the product with $2 \mu \mathrm{L}$ of ExoSAP-IT $^{\mathrm{sm}}$ (Thermo Fisher, MA, USA) and incubated at $37^{\circ} \mathrm{C}$ for 15 minutes. After this, the mixture was incubated at $80^{\circ} \mathrm{C}$ for 15 minutes and then stored at $4^{\circ} \mathrm{C}$ until use. A volume of $3 \mu \mathrm{L}$ of each of these cleaned products was then pipetted into 2 tubes and $6 \mu \mathrm{L}$ of RNAse-free water added to each tube. A volume of $1 \mu \mathrm{L}$ of the forward primer was added to one tube and the same volume of nested reverse primers to the other tube to give a $10 \mu \mathrm{L}$ total volume per tube. Sanger sequencing was done by Seqlab GmbH, GÖttingen Germany.

All obtained sequences from Seqlab were compared to sequences deposited on GenBank via the BLAST Algorithm and were aligned together with reference sequences from the Genbank. A cladogram was constructed using Bayesian inference which compared the partial $\mathrm{BCoV}$ RdRp sequence obtained from this study to those from different species and countries.

\section{Statistical Analysis}

Categorical data were presented as frequencies (percentages). Analysis of sequence data was done using the online BLAST tool (http://blast.ncbi.nlm.nih.gov/Blast.cgi) to identify homologous strains. Construction of the phylogenetic tree was done by Bayesian inference using MrBayes [28] plugin in Geneious Prime 2019 (http:// www.geneious.com). Graphical presentation was performed using GraphPad Prism 7 version 7.04 (GraphPad Software, Inc., La Jolla, California USA).

\section{Abbreviations}

BCoV: bovine coronavirus; RdRp: RNA-dependent RNA polymerase; RTPCR: reverse transcriptase polymerase chain reaction; NCBI: National Center for Biotechnology Information

\section{Acknowledgements}

The authors are grateful to the Veterinary Service Directorates of Upper East, Northern, Greater Accra and Volta regions of Ghana, former graduate students on BAT II Project, Kumasi Center for Collaborative Research, KNUST and all who actively participated in the study.

\section{Authors' contributions}

$C D, Y A S, A S$ and $M O$ designed the study, supervised the research and laboratory analysis, drafted and revised the manuscript. VB was involved in the collection of data, laboratory analysis, drafting and revision of the manuscript. PED, RY, JL, YOF, OA, BE, WT, SO and CA were involved in the collection of data and laboratory analysis. EWO and PED was involved in the data analysis and interpretation, drafting and revision of the manuscript. RF was involved in the drafting and revision of the manuscript. All authors read and approved the final manuscript.

\section{Funding}

This work was supported by Deutsche Forschungsgemeinschaft under a Grant to YAS. And CD (DR 772/12- 1). The funding body had no role in the design of the study, sample collection, statistical analysis and interpretation and writing of the manuscript. 


\section{Availability of data and materials}

The datasets generated and/or analysed during the current study are accessible from Figshare repository: https://doi.org/10.6084/m9.figshare.12830405.v1. The sequence data are available at the National Center for Biotechnology Information (NCBI) (Genbank accession numbers: MT711466-9).

\section{Ethics approval and consent to participate}

This study was approved by the Wildlife division of the Ghana Forestry Commission (Approval number: AO4957). Written informed consent was obtained from all owners whose animals were used in the study.

\section{Consent for publication}

Not applicable.

\section{Competing interests}

The authors declare that they have no competing interests.

\section{Author details}

'Department of Clinical Microbiology, Kwame Nkrumah University of Science and Technology, Kumasi, Ghana. ${ }^{2}$ School of Veterinary Medicine, Kwame Nkrumah University of Science and Technology, Kumasi, Ghana. ${ }^{3}$ Kumasi Centre for Collaborative Research in Tropical Medicine, Kumasi, Ghana. ${ }^{4}$ Department of Theoretical and Applied Biology, Kwame Nkrumah University of Science and Technology, Kumasi, Ghana. ${ }^{5}$ Department of Medical Laboratory Technology, Kwame Nkrumah University of Science and Technology, Kumasi, Ghana. ${ }^{6}$ Institute of Virology, Universitätsmedizin Berlin, Charite, Germany. ${ }^{7}$ Department of Animal Science, Kwame Nkrumah University of Science and Technology, Kumasi, Ghana. ${ }^{8}$ Department of Agroforestry, Kwame Nkrumah University of Science and Technology, Kumasi, Ghana. ${ }^{9}$ Department of Molecular Medicine, Kwame Nkrumah University of Science and Technology, Kumasi, Ghana. ${ }^{10}$ Department of Wildlife and Range Management, Kwame Nkrumah University of Science and Technology, Kumasi, Ghana.

\section{Received: 23 April 2020 Accepted: 1 October 2020}

Published online: 27 October 2020

\section{References}

1. Yang D, Leibowitz JL. The structure and functions of coronavirus genomic $3^{\prime}$ and 5' ends. Virus Res. 2015;206:120-33.

2. Oma VS, Tråvén M, Alenius $S$, et al. Bovine coronavirus in naturally and experimentally exposed calves; viral shedding and the potential for transmission. Virol J. 2016;13(1):100.

3. Pfefferle S, Oppong S, Drexler JF, et al. Distant relatives of severe acute respiratory syndrome coronavirus and close relatives of human coronavirus 229E in bats, Ghana. Emerg Infect Dis. 2009;15(9):1377.

4. Lai MM, Cavanagh D. The molecular biology of coronaviruses. Advances in virus research. Vol. 48: Elsevier; 1997. p. 1-100.

5. Boileau MJ, Kapil S. Bovine coronavirus associated syndromes. Veterinary Clinics: Food Animal Practice. 2010;26(1):123-46.

6. Ksiazek TG, Erdman D, Goldsmith CS, et al. A novel coronavirus associated with severe acute respiratory syndrome. New England journal of medicine. 2003;348(20):1953-66.

7. Clark M. Bovine coronavirus. Br Vet J. 1993;149(1):51-70

8. Park S, Kim G, Choy H, et al. Dual enteric and respiratory tropisms of winter dysentery bovine coronavirus in calves. Archives of virology. 2007;152(10): 1885-900.

9. Lojkić I, Krešić N, Šimić I, et al. Detection and molecular characterisation of bovine corona and toroviruses from Croatian cattle. BMC Vet Res. 2015;11(1):202.

10. Park S, Jeong C, Yoon S, et al. Detection and characterization of bovine coronaviruses in fecal specimens of adult cattle with diarrhea during the warmer seasons. J Clin Microbiol. 2006;44(9):3178-88.

11. Decaro N, Campolo M, Desario C, et al. Respiratory disease associated with bovine coronavirus infection in cattle herds in Southern Italy. J Vet Diagn Invest. 2008;20(1):28-32.

12. Tråvén $M, N a ̈ s l u n d ~ K$, Linde $N$, et al. Experimental reproduction of winter dysentery in lactating cows using BCV-comparison with BCV infection in milk-fed calves. Veterinary microbiology. 2001;81(2):127-51.

13. Saif $\amalg$. Bovine respiratory coronavirus. Veterinary Clinics: Food Animal Practice. 2010;26(2):349-64.
14. Gumusova O, Yazici Z, Albayrak H, et al. First report of bovine rotavirus and bovine coronavirus seroprevalance in goats in Turkey. Vet glasnik. 2007;61:75-9.

15. Eisa M, Mohamed A. Role of enteric pathogens in enteritis in lambs, goat kids and children and their zoonotic importance. Vet Med J Giza. 2004:52:41-59.

16. Tråvén M, Carlsson U, Lundén $A$, et al. Serum antibodies to bovine coronavirus in Swedish sheep. Acta Vet Scand. 1999;40:69-74.

17. Pass $D$, Penhale $W$, Wilcox $G$, et al. Intestinal coronavirus-like particles in sheep with diarrhoea. Vet Rec. 1982;111:106-7.

18. Durham P, Stevenson B, Farquharson B. Rotavirus and coronavirus associated diarrhoea in domestic animals. New Zealand Veterinary Journal. 1979;27:30-2.

19. Burimuah V, Sylverken A, Owusu M, et al. Sero-prevalence, cross-species infection and serological determinants of prevalence of Bovine Coronavirus in Cattle, Sheep and Goats in Ghana. Veterinary Microbiology. 2019:108544.

20. Kumar S, Rai R, Dhama K, et al. Detection of bovine coronavirus in calf diarrheic samples by indirect antigen capture ELISA and RT-PCR. Research Opinions in Animal Veterinary Sciences. 2013;3(8):225-34.

21. Lathrop SL, Wittum TE, Brock KV, et al. Association between infection of the respiratory tract attributable to bovine coronavirus and health and growth performance of cattle in feedlots. American journal of veterinary research. 2000;61(9):1062-6.

22. Cho K-O, Hoet AE, Loerch SC, et al. Evaluation of concurrent shedding of bovine coronavirus via the respiratory tract and enteric route in feedlot cattle. American journal of veterinary research. 2001;62(9):1436-41.

23. Hasoksuz M, Hoet AE, Loerch SC, et al. Detection of respiratory and enteric shedding of bovine coronaviruses in cattle in an Ohio feedlot. J Vet Diagn Invest. 2002;14(4):308-13.

24. Smith DR, Fedorka-Cray PJ, Mohan R, et al. Epidemiologic herd-level assessment of causative agents and risk factors for winter dysentery in dairy cattle. American journal of veterinary research. 1998:59:994-1001.

25. Tråvén M, Verdier K, Larsen LE et al, editors. Diagnosis and epidemiology of bovine coronavirus in Swedish neonatal dairy and beef calves. 7th International Congress of Veterinary Virology; 2006

26. van Elden $\sqcup$, Anton MAM, van Alphen F, et al. Frequent detection of human coronaviruses in clinical specimens from patients with respiratory tract infection by use of a novel real-time reverse-transcriptase polymerase chain reaction. The Journal of infectious diseases. 2004;189(4):652-7.

27. da Silva Filho LVRF, Zerbinati RM, Tateno AF, et al. The differential clinical impact of human coronavirus species in children with cystic fibrosis. The Journal of infectious diseases. 2012;206(3):384-8.

28. Huelsenbeck JP, Ronquist F. MRBAYES: Bayesian inference of phylogenetic trees. Bioinformatics. 2001;17(8):754-5.

\section{Publisher's Note}

Springer Nature remains neutral with regard to jurisdictional claims in published maps and institutional affiliations.

\section{Ready to submit your research? Choose BMC and benefit from:}

- fast, convenient online submission

- thorough peer review by experienced researchers in your field

- rapid publication on acceptance

- support for research data, including large and complex data types

- gold Open Access which fosters wider collaboration and increased citations

- maximum visibility for your research: over $100 \mathrm{M}$ website views per year

At BMC, research is always in progress.

Learn more biomedcentral.com/submissions 